\title{
Galápagos Rail Laterallus spilonotus population change associated with habitat invasion by the Red-barked Quinine Tree Cinchona pubescens
}

\author{
W. GREGORY SHRIVER, JAMES P. GIBBS, HARA W. WOLTZ, NICOLE P. \\ SCHWARZ and MARGARET A. PEPPER
}

\begin{abstract}
Summary
Species on oceanic islands are more likely to be endemic as well as more extinction-prone than those on continents. The Galápagos Rail Laterallus spilonotus, endemic to the Galápagos Archipelago, is presently known to occur on just four of its seven previously occupied islands and is facing multiple threats to its persistence. In this study, we compared the rail's occurrence and abundance at 193 survey points between 2000 and 2007 on Santa Cruz Island and examined the influence of an invasion of the habitat of the species by the exotic Red-barked Quinine Tree Cinchona pubescens. We detected a $13 \%$ reduction in rail occurrence and a $31 \%$ reduction in abundance between 2000 and 2007. Rail abundance declined more in low elevation areas $(<719 \mathrm{~m})$ and outside of Cinchona pubescens removal areas but not in areas where Cinchona pubescens was removed. Insofar as Galápagos Rails responded positively to management actions that promote and maintain native vegetation, we conclude that restoration projects that restore native vegetation communities benefit this apparently declining endemic bird for which more focused conservation attention is warranted.
\end{abstract}

\section{Introduction}

Extinction rates among island populations are disproportionately higher than mainland populations, and are highest for island endemic species (Pimm et al. 1988). Birds exemplify this trend: only $17 \%$ of bird species are island endemics yet $90 \%$ of all bird extinctions since 1600 are accounted for by island-based populations. Among the many causes of extinctions, habitat destruction and introduction of alien species are responsible for most losses of island forms (Johnson and Stattersfield 1990).

The number of alien plant introductions and the extent of invasive plant species coverage in the Galápagos Islands have increased dramatically, concurrent with increases in human populations (Mauchamp 1997). Over at least the past 20 years, the Galápagos Islands have undergone profound alterations as a result of plant and animal introductions (Lawesson and Ortiz 1990, Itow 2003). Presently, alien plant and animal populations, especially on the human populated islands of the Galápagos Archipelago (Floreana, Isabela, Santa Cruz, San Cristobal), are one of the greatest threats to terrestrial ecosystems (Walsh et al. 2008) and many such species such as Galapagos Petrel Pterodroma phaeopygia (Cruz-Delgado in press) and Medium Tree Finch Camarhynchus pauper ( $\mathrm{O}^{\prime}$ Connor in press) are globally threatened by such invasives.

The Galápagos Islands host an endemic rail, Laterallus spilonotus, which once occurred on the seven major islands high enough to support humid zone vegetation (Franklin et al. 1979, Gibbs et al. 2003). Presently, basic information about the biology of the species including its demography, habitat use, and dispersal are lacking. Because rail species that occupy islands 
in the Pacific Ocean have experienced the highest rate of extinction among all bird groups (Steadman 1995), and given the multiple threats facing the Galápagos species, this species is listed as 'Vulnerable' on the IUCN Red List (IUCN 2007).

Recent work indicated that Galápagos Rails recovered quickly after native vegetation recovery following goat eradications but little else is known of its interactions with invasive species (Donlan et al. 2007). One invasive species of particular concern in the humid highlands where the rail occurs is Cinchona pubescens, the Red-barked Quinine Tree. C. pubescens, was first introduced to the Galápagos in the 1940s when it was planted in the agricultural zone (Hamann 1979, Van der Werff 1979, Shimizu 1997, Lundh 2006) and spread quickly throughout the Miconia and fern-sedge zones via its wind-dispersed seeds (Schofield 1989). In the late 1970s an eradication project was initiated; by 1981 over 30,000 trees were destroyed (Van der Werff 1979, Touc 1983, Hamann 1984). Since that time, the invasion has continued to spread, with a recent eradication programme implemented between 2001 and 2006. C. pubescens presently covers at least 11,000 ha in the highlands of Santa Cruz Island and is now the dominant vegetation in the Miconia and fern-sedge zones (Macdonald et al. 1988, Buddenhagen and Ya'nez 2005, Jäger et al. 2007).

The ecological effects of the $C$. pubescens invasions have been recently quantified. Jäger et al. (2007) showed a reduction in native plant species richness and cover associated with proximity to C. pubescens. Gibbs et al. (2003) showed that Galápagos Rails were more likely to occur in areas dominated by fern-sedge cover even when the majority of the Santa Cruz highland zones had greater than $50 \%$ C. pubescens cover. From 2001 to the present, the Galápagos National Park implemented a C. pubescens removal project in sections of the Santa Cruz highlands in an attempt to restore some of these areas. Previous rail survey locations in the Gibbs et al. (2003) study were fortuitously located both inside and outside of C. pubescens control areas. To exploit the opportunity presented by this quasi-experiment we contrasted the rail population between 2000 and 2007 to estimate the effects of $C$. pubescens control on rail occurrence and abundance.

\section{Methods}

Our surveys were focused on the Miconia and fern-sedge zones of Santa Cruz Island, Galápagos National Park, Ecuador ( $0^{\circ} 38^{\prime} 14.12^{\prime \prime} \mathrm{S}, 90^{\circ} 22^{\prime} 05.30^{\prime \prime} \mathrm{W}$; Fig. I). Six vegetation zones exist throughout the archipelago, all of which are extant on Santa Cruz Island (Wiggins and Porter 1971, Schofield 1989). The Miconia zone extends from approximately 500 to $680 \mathrm{~m}$ above sea level and is dominated by the endemic shrub Miconia robinsoniana, many fern species (mainly Pteridium arachnoideum, Blechnum polypodioides and B. occidentale), lycopods, and herbaceous flowering plants (Schofield 1989). The fern-sedge zone, dominated by P. arachnoideum, reaches from about $570 \mathrm{~m}$ to the island peak at $864 \mathrm{~m}$ (Jäger et al. 2007). The fern-sedge zone is comprised of low-growing vegetation including ferns, grasses, sedges and herbs (Schofield 1989).

In 2007, we relocated with hand-held GPS units 193 survey points (Fig. 1) that were established and surveyed in January 2000 by Gibbs et al. (2003). We used the same observers and surveyed during the same period (28 December-25 January) to detect rail occurrence at each location during both 2000 and 2007 . We also used the same sampling protocol as in other surveys (Rosenberg 1990, Gibbs et al. 2003). In this protocol, rail detections are based on counts of rails responding to calls broadcast from fixed-radius $(25 \mathrm{~m})$ survey points spaced $150 \mathrm{~m}$ apart. We used this sampling point spacing to avoid double counting rails based on the lack of territory overlap found by Franklin et al. (1979). We counted rails within a $25 \mathrm{~m}$ radius of each survey location for three minutes total ( 1 min silent, 1 min playback, 1 min silent). Rail calls, which consisted of a mixture of the primary calls of the species (the chichichichirrooo, chirr, and rattle calls), were obtained from the Cornell University Laboratory of Natural Sounds. At each survey site, calls were broadcast from a small tape player, handheld $1.5 \mathrm{~m}$ above the ground, for 15 seconds in each cardinal direction. We estimated an index of rail abundance as the total rails counted at each survey location based on those birds detected within $25 \mathrm{~m}$. 


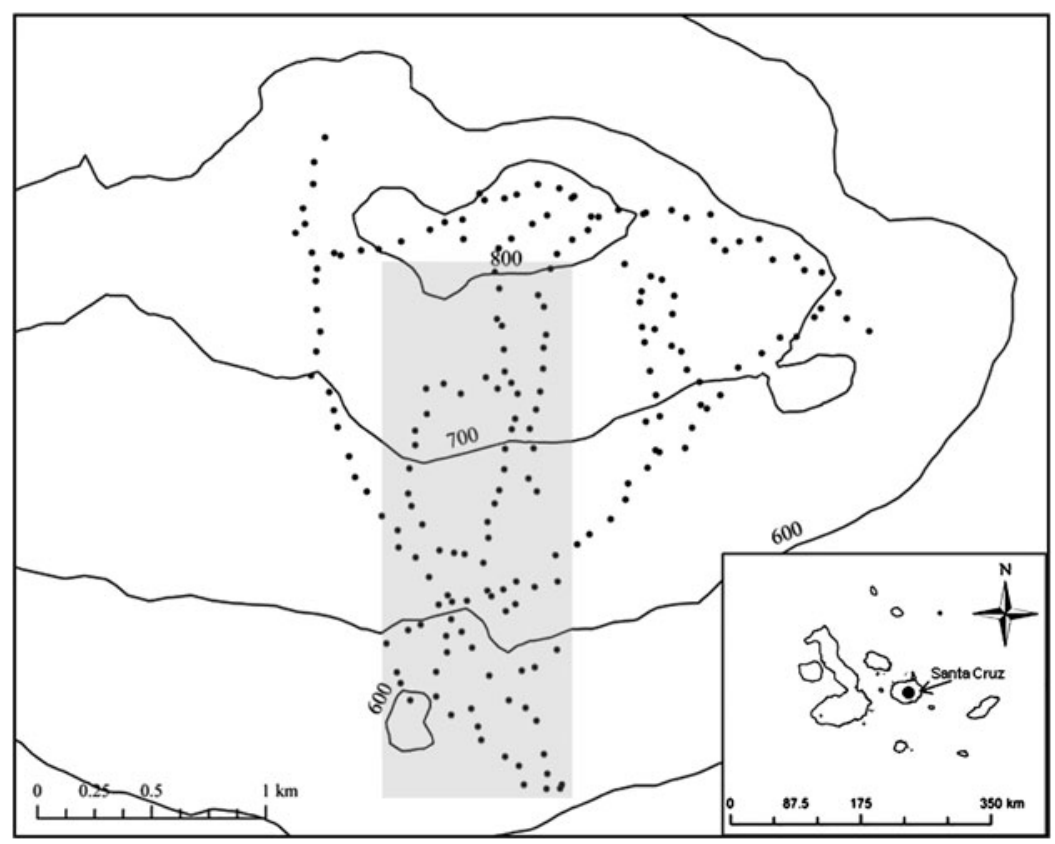

Figure 1. Locations of Galápagos Rail survey sites on Santa Cruz Island, Galápagos, Ecuador.

To assess differences in Galápagos Rail presence/absence between 2000 and 2007, we used McNemar's G-test (Zar 1999) because plots were fixed (data used for 2007 were from the first complete visit to the same points surveyed in 2000 and best matched the dates of the 2000 survey) and data were dichotomous (rail present versus rail absent). For this comparison, we categorised survey points into four groups based on their status during each survey period (2000-2007): 1) absent-present - rails absent in 2000 and present in 2007; 2) present-present - rails detected during both survey periods, 3) absent-absent - rails not detected in either time period, and 4) present-absent - rails detected in 2000 but not in 2007 . We used logistic regression to determine the overall effects of elevation and C. pubescens removal on changes in rail occurrence from 2000 to 2007 (Hosmer and Lemeshow 2000). For this analysis, we selected sites where rails were detected in at least one of the two years and coded sites as having no change (o) in abundance or a decline (I) in abundance. We included an interaction term between elevation and C. pubescens removal zone to determine if changes in rail occurrence were consistent among elevation and C. pubescens removal areas.

To elucidate differences in the relative abundance of rails over time, we used non-parametric ANOVA (Kruskal-Wallis, Zar 1999) to compare the relative abundance estimates of rails in 2000 to estimates in 2007 . We compared rail abundance between 2000 and 2007) across (I) all survey locations, (2) within four elevation zones that correspond to the upper edge of the agricultural zone bordering the park (502-627 m), the Miconia zone (628-686 m), the fern-sedge zone (687$717 \mathrm{~m}$ ) and the top of the island, Cerro Crocker (718-864 m), known to be a high rail density area (Rosenberg 1990, Gibbs et al. 2003), and (3) between C. pubescens removal zones (removed or not removed). These zones overlapped completely in elevation; the areas where $C$. pubescens was removed ranged from 502 to $838 \mathrm{~m}$ and the areas where C. pubescens was not removed ranged from 518 to $864 \mathrm{~m}$ in elevation. We performed all analyses using SPSS (version 15.0) and interpreted difference at $\alpha<$ o.1o to reduce Type II error given the risks of missing potentially significant changes in a population of an endangered species. 


\section{Results}

Of the 193 points surveyed in both 2000 and 2007 , we detected rails at 31 (16\%) points surveyed in 2007 compared to 56 points $(29 \%)$ in 2000 . We detected rails at 17 points $(8 \%)$ in 2007 where we did not detect rails in 2000 and 42 points $(22 \%)$ where we detected rails in 2000 but not in 2007 . We detected rails at $14(7 \%)$ of the points during both surveys. Together, these data represent a significant decline $\left(\right.$ McNemar's $\left._{\mathrm{adj}}=10.907, P=0.002\right)$ in rail detections between 2000 and 2007. The logistic regression analysis indicated a significant effect of elevation ( $\beta=-0.968 \pm 0.444, P=0.029$ ) but no effect associated with $C$. pubescens removal zone $(\beta=-2.354 \pm 1.906, P=0.217)$ and no interaction between elevation and $C$. pubescens removal zone $(\beta=0.444 \pm 0.556, P=0.424)$.

Rail abundance was $31 \%$ greater in 2000 than $2007\left(\chi^{2}=5.632, P=0.018\right)$ : we counted 73 rails (mean $=0.40 \pm 0.05$ rails $/$ point) on the 193 points in 2000 and 51 rails (mean $=0.26 \pm$ 0.05 rails / point) at the same locations in 2007 . We detected a $75 \%$ decline in rail abundance between 2000 and 2007 on survey plots from 502 to $627 \mathrm{~m}$ and a $71 \%$ decline on survey plots from 628 to $686 \mathrm{~m}$ (Table 1 ). Rail abundance declined by $58 \%$ on survey plots located between 687 and $718 \mathrm{~m}$ but this difference was not significant (Table 1). Rail abundance was unchanged on the highest elevation $(>717 \mathrm{~m}$ ) survey plots from 2000 to 2007 (Table 1 ). Rail abundance outside the C. pubescens removal zone in 2000 was $44 \%$ greater than on the same plots in 2007 (Table I) whereas we did not detect a difference in rail abundance between 2000 and 2007 on survey plots where C. pubescens was removed (Table I). Rail detections in the Santa Cruz highlands declined from being detected on $36 \%$ of the survey points in 1986 (Rosenberg 1990), to $27 \%$ in 2000 (Gibbs et al. 2003), to $16 \%$ in 2007.

\section{Discussion}

After our surveys in 2000, we concluded that the Galápagos Rail population of the Santa Cruz highlands was in decline but still abundant and therefore at a critical juncture (Gibbs et al. 2003). After revisiting these same sites in 2007 and detecting yet a further and more serious decline we contend that there should be heightened concern for the persistence of this, one of the largest and most central, populations of the Galápagos Rail. We estimated a minimum number of detections of 78 rails on Santa Cruz in 2000 but 51 in 2007 based on identical survey methods at same time of year. The present analyses indicated that the Galápagos Rail decline on Santa Cruz has continued except in areas where $C$. pubescens has been removed and at elevations $>718 \mathrm{~m}$. This indicates that the efforts to control the non-native invasive plant where it has become established and to maintain high elevation habitat in native vegetation can help maintain Galápagos Rails. Given the constraints of small populations and habitat limitations inherent with endemic island species (Pimm et al. 1988), reductions in available habitat and habitat quality will only increase extinction risk.

Table 1. Changes in Galápagos Rail abundance related to elevation and C. pubescens removal 2000-2007 on Santa Cruz Island, Ecuador.

\begin{tabular}{|c|c|c|c|c|c|c|c|c|c|}
\hline & \multirow{2}{*}{$\begin{array}{l}\text { Survey Point } \\
\text { Location } \\
\text { (\# points) }\end{array}$} & \multicolumn{3}{|l|}{2000} & \multicolumn{3}{|l|}{2007} & \multirow[t]{2}{*}{$\chi^{2}$} & \multirow[t]{2}{*}{$P$} \\
\hline & & $\begin{array}{l}\text { Total } \\
\text { Count }\end{array}$ & $\begin{array}{l}\text { Mean / } \\
\text { point (SE) }\end{array}$ & $\begin{array}{l}\text { \% points } \\
\text { detected }\end{array}$ & $\begin{array}{l}\text { Total } \\
\text { Count }\end{array}$ & $\begin{array}{l}\text { Mean / } \\
\text { point (SE) }\end{array}$ & $\begin{array}{l}\% \text { points } \\
\text { detected }\end{array}$ & & \\
\hline \multirow{4}{*}{$\begin{array}{c}\text { Elevation } \\
\text { Zone }\end{array}$} & $502-627 \mathrm{~m}(49)$ & 9 & $0.18(0.06)$ & 16 & 2 & $0.04(0.03)$ & $\mathrm{O} 4$ & 4.018 & 0.045 \\
\hline & $628-686 m(48)$ & 17 & $0.35(0.11)$ & 25 & 5 & $0.10(0.05)$ & o8 & $4 \cdot 544$ & 0.033 \\
\hline & $687-717 \mathrm{~m} \mathrm{(32)}$ & 12 & $0.38(0.13)$ & 25 & 5 & $0.16(0.08)$ & 13 & 1.727 & 0.189 \\
\hline & $718-864 \mathrm{~m}(64)$ & 40 & $0.62(0.10)$ & 42 & 39 & 0.61 (0.11) & 38 & 0.084 & 0.771 \\
\hline \multirow{2}{*}{$\begin{array}{l}\text { C. pubescens } \\
\text { removal zone }\end{array}$} & not removed (96) & 52 & $0.55(0.09)$ & 37 & 30 & $0.31(0.07)$ & 20 & 5.682 & 0.017 \\
\hline & removed (97) & 26 & $0.26(0.06)$ & 20 & 21 & $0.22(0.06)$ & 14 & 0.887 & 0.346 \\
\hline
\end{tabular}


How the ongoing C. pubescens invasion might negatively affect the Galápagos Rail is unknown. Jäger et al. (2007) found native and endemic plant species richness and cover decreased as proximity to $C$. pubescens tress increased. The reduction in these attributes was most pronounced in the fern-sedge zone where we detected the greatest Galápagos Rail abundance. The C. pubescens canopy also reduced photosynthetically active radiation (PAR) by up to $85 \%$ (Jäger et al. 2007), which likely has impacts on invertebrate biomass, an important food source for Galápagos Rails (Franklin et al. 1979). If C. pubescens is truly an 'ecosystem engineer', as suggested by Jäger et al. (2007), then the cascading trophic effects caused by changes in plant species composition and PAR suppression may well be altering the Miconia and fern-sedge zones of Santa Cruz Island to a point where Galápagos Rail survival and fecundity may be being reduced, a compelling hypothesis worthy of further investigation.

Based on our surveys, Galápagos Rails can be characterised with other island endemic rails as among the most vulnerable bird species to extinction. Of the 22 named species in the family Rallidae that have gone extinct since the 160os, 21 (95\%) occurred only on islands. Presently, all four (100\%) 'Critically Endangered' species (Samoan Moorhen Gallinula pacifica, Zapata Rail Cyanolimnas cerverai, Makira Moorhen Gallinula silvestris, New Caledonian Rail Gallirallus lafresnayanus and Zapata Rail Cyanolimnas cerverai) and the one species that is extinct in the wild (Guam Rail Gallirallus owstoni) are island endemics. Also, seven of the II $(64 \%)$ Endangered' and 12 of $18(67 \%)$ rail species listed as 'Vulnerable' occur only on islands (IUCN 2007; downloaded from http://www.birdlife.org on 18/8/2010). Extinction probability for island avifauna is 40 times greater than for congeneric continental populations (Trevino et al. 2006) with the three primary causes of island endemic birds being habitat destruction, limited range, and introduction of alien species (Stattersfield et al. 2007). Galápagos Rails seem to respond positively to management actions that maintain native vegetation either by eliminating introduced herbivores (Donlan et al. 2007) or by direct removal of the invasive plant (this study), making restoration projects that restore native vegetation communities to rail habitat worthy endeavours. Sites with rails detected had more fern cover and less C. pubescens. Native vegetation in the highlands zone of Santa Cruz is often displaced by invading plant species (Jäger et al. 2007) and these observations reinforce the notion that maintaining native vegetation within Galápagos Rail habitat is important for its continued survival. In addition, we suggest that the species would benefit from further research into its basic biology, especially its demography, to permit a better understanding of Galápagos Rail population viability and the demographic impact of C. pubescens invasion, as well as further population and distribution monitoring given its precarious status. Presently, essentially no demographic (e.g. clutch size, nest survival, juvenile or adult survival) or population genetic (e.g. differentiation among islands) data exist for this species, which limits our ability to make predictions about Galápagos Rail population viability.

\section{Acknowledgements}

We are grateful to Sixto Naranjo and the staff at Parque Nacional Galápagos for permission to access the highlands of Santa Cruz and assistance in implementing the surveys. We thank Susana Cardenas and the staff at the Charles Darwin Research Station for exceptional support during unanticipated and difficult phases of this project. This research was funded by the University of Delaware Research Foundation and the American Wildlife Research Foundation.

\section{References}

Buddenhagen, C. and Ya'nez, P. (2005) The cost of quinine Cinchona pubescens control on Santa Cruz Island, Galápagos. Galápagos Research 63: 32-36.
Cruz-Delgado, F., González, J. A. and Wiedenfeld, D. A. (in press) Breeding biology of the Critically Endangered Gálapagos Petrel Pterodroma phaeopygia on San 
Cristóbal Island: conservation and management implications. Bird Conserv. Int. doi:10.1017/So95927091000002X.

Donlan, C. J., Campbell, K., Cabrera, W., Lavoie, C., Carrion, V. and Cruz, F. (2007) Recovery of the Galápagos rail (Laterallus spilonotus) following the removal of invasive mammals. Biol. Conserv. 138: 520-524. Franklin, A. B., Clark, D. A. and Clark, D. B. (1979) Ecology and behavior of Galápagos Rail. Wilson Bull. 91: 202-221.

Gibbs, J. P., Shriver, W. G. and Vargas, H. (2003) An assessment of a Galápagos rail population over thirteen years (1986 to 200o). J. Field Ornith. 74: 136-140.

Hamann, O. (1979) On climatic conditions, vegetation types, and leaf size in the Galápagos Islands. Biotropica 11: 101-122.

Hamann, O. (1984) Changes and threats to the vegetation, Pp. 115-131 in R. Perry, ed. Key environments. Galápagos. Oxford, UK: Pergamon Press.

Hosmer, D. W. and Lemeshow, S. (2000) Applied logistic regression. $2^{\text {nd }}$ edition. Hoboken, NJ: John Wiley and Sons, Inc.

Itow, S. (2003) Zonation pattern, succession process and invasion by aliens in speciespoor vegetation of the Galápagos Islands. Global Environ. Res. 7: 39-58.

IUCN (2007) IUCN Red List of threatened species. www.iucnredlist.org. Downloaded on 19 September 2008.

Jäger, H., Tye, A. and Kowarik, I. (2007) Tree invasion in naturally treeless environments: Impacts of quinine (Cinchona pubescens) trees on native vegetation in Galápagos. Biol. Conserv. 140: 297-307.

Johnson, T. H. and Stattersfield, A. J. (1990) A global review of island endemic birds. Ibis 132: $167-180$.

Lawesson, J. E. and Ortiz, L. (1990) Plantas introducidas en las Islas Galápagos. Pp. 201-210 in J. E. Lawesson, O. Hamann, G. Rogers, G. Reck and U. Ochoa, eds. Botanical research and management in Galápagos. St Louis, MO: Missouri Botanical Garden Press. (Monographs in Systematic Botany No. 32).

Lundh, J. P. (2006) The farm area and cultivated plants on Santa Cruz, 1932-1965, with remarks on other parts of Galápagos. Galápagos Res. 64: 12-25.
Macdonald, I. A. W., Ortiz, L., Lawesson, J. E. and Nowak, J. B. (1988) The invasion of highlands in Galápagos by the red quininetree (Cinchona succirubra). Environ. Conserv. 15: 215-220.

Mauchamp, A. (1997) Threats from alien plant species in the Galápagos islands. Conserv. Biol. 11: 260-263.

O'Connor, J. A., Sulloway, F. J. and Kleindorfer, S. (in press) Avian population survey in the Floreana highlands: is Darwin's Medium Tree Finch declining in remnant patches of Scalesia forest? Bird Conserv. Int. doi:10.1017/So959270910000195.

Pimm, S. L., Jones, H. L. and Diamond, J. (1988) On the risk of extinction. Am. Nat. 132: $757-785$.

Rosenberg, D. K. (1990) The impact of introduced herbivores on the Galápagos Rail (Laterallus spilonotus). Monogr. Syst. Bot. Missouri Bot. Gard. 32: 169-178.

Schofield, E. K. (1989) Effects of introduced plants and animals on island vegetation: Examples from the Galápagos Archipelago. Conserv. Biol. 3: 227-238.

Shimizu, Y. (1997) Competitive relationships between tree species of Scalesia (S. pedunculata, S. cordata, S. microcephala) and introduced plants (Cinchona succirubra, Psidium guajava, Lantana camara) with reference to regeneration mechanism of Scalesia forests in the Galápagos Islands. Regional Views 11: 23-172.

Stattersfield, A. J., Crosby, M. J., Long, A. J. and Wege, D. C. (2007) Endemic bird areas of the world: priorities for biodiversity conservation. Cambridge, UK: BirdLife International.

Steadman, D. W. (1995) Prehistoric extinctions of Pacific island birds: Biodiversity meets zooarchaeology. Science 267: 1123-1131.

Touc, L. T. (1983) Some thoughts on the control of introduced plants. Noticias de Galápagos 37: 25-26.

Trevino, H. S., Skibiel, A. L., Karels, T. J. and Dobson, F. S. (2006) Threats to avifauna on oceanic islands. Conserv. Biol. 21: 125-132.

Van der Werff, H. (1979) Conservation and vegetation of the Galápagos Islands. Pp. 391-404 in D. Bramwell, ed. Plants and islands. New York: Academic Press.

Walsh, S. J., McCleary, A. L., Mena, C. F., Shao, Y., Tuttle, J. P., Gonzalez, A. and 
Atkinson, R. (2008) QuickBird and Hyperion data analysis of an invasive plant species in the Galápagos Islands of Ecuador: Implications for control and land use management. Remote Sens. Environ. 112: 1927-1941.
Wiggins, I. L. and Porter, D. M. (1971) Flora of the Galápagos Islands. Stanford, CA: Stanford University Press.

Zar, J. H. (1999) Biostatistical analysis. Upper Saddle River, NJ: Prentice Hall.

\section{W. GREGORY SHRIVER*}

Department of Entomology and Wildife Ecology, University of Delaware, Newark, DE 19717, USA.

\section{JAMES P. GIBBS}

State University of New York, College of Environmental Science and Forestry, I Forestry Drive, Syracuse, New York 13210, USA.

\section{HARA W. WOLTZ}

Columbia University Department of Ecology, Evolution, and Environmental Biology 1oth Floor Schermerhorn Ext. 1200 Amsterdam Avenue New York, New York 10027, USA.

\section{NICOLE P. SCHWARZ}

Charles Darwin Research Station, Puerto Ayora, Santa Cruz Island Galápagos, Ecuador.

\section{MARGARET A. PEPPER}

Department of Entomology and Wildlife Ecology, University of Delaware, Newark, DE 19717, USA.

*Author for correspondence; e-mail gshriver@udel.edu

Received 8 April 2010; revision accepted 7 July 2010;

Published online 3 November 2010 